\title{
GIÁ TRI SIÊU ÂM TRONG CHẨN ĐOÁN HACCH CỔ DI CĂN Ở BỆNH NHÂN UNG THƯ TUYẾN GIÁP THỂ BIỆT HÓA SAU PHẪU THUÂTT VÀ Đİ̂̀U TRI 131I
}

\section{TÓM TẮT}

Mục đích: Mục đích của nghiên cứu là xác định giá trị của siêu âm $B$ Mode và Doppler màu trong chẩn đoán di căn hạch cổ ở bệnh nhân ung thư tuyển giáp thể biệt hóa sau phẫu thuât và điêu trị ${ }^{131} \mathrm{I}$. Đối tượng và phương pháp nghiên cứu: Nghiên cứu hồi cứu kết hợp tiến cứu, mô tả cắt ngang 61 bệnh nhân với 123 hạch cổ. Bệnh nhân được phẫu thuật vét hạch làm mô bệnh học tại Bệnh viện Trung ương Quân đội 108 trong thời gian từ tháng 10/2020 đến tháng 4/2021. Kết quả: Chúng tôi đã tiến hành siêu âm ơ 123 hạch vùng cổ. Đối chiếu với kết quả giải phẫu bệnh, có 73 hach di căn, 50 hạch không di căn. Hình dạng tròn, mất rốn hạch, hồi âm, vôi hóa và mạch máu bất thường gặp ở hạch di căn hơn so với hạch không di căn, trong khi ranh giới và kích thước không khác biệt đáng kể. Độ nhạy, độ đặc hiệu, giá trị tiên đoán dương, giá trị tiên đoán âm, độ chính xác của phương pháp siêu âm 2D kết hợp siêu âm Dopper lần lượt là $90,4 \%, 84 \%, 89,2 \%, 85,7 \%$ và $87,8 \%$. Kết luận: Trong nghiên cứu này, siêu âm 2D kêt hợp siêu âm Doppler màu có giá trị rất cao trong chẩn đoán hach cổ ác tính. Việc thực hiện siêu âm đánh giá hạch cổ góp vai trò giảm thiểu nhu cầu chọc tế bào/ sinh thiết hach cổ lành tính.

Tư khóa: siêu âm B-mode, siêu âm Doppler màu, ung thư tuyến giáp, di căn hạch.

\section{SUMMARY \\ VALUE OF ULTRASOUND IN THE DIAGNOSIS OF CERVICAL LYMPH NODES METASTASIS IN PATIENTS WITH PAPILLARY THYROID AFTER \\ SURGERY AND TREATMENT WITH ${ }^{131}$ I}

Background: The purpose of the study was to evaluate the characters of B Mode and color Doppler ultrasound (CDUS) in diagnosis cervical lymph nodes metastasis in patients with papillary thyroid after surgery and treatment with ${ }^{131}$ I. Materials and Methods: Retrospective combined with prospective research, cross-sectional description of 61 patients with 123 lymph nodes, surgical and histopathological in 108 Military Central Hospital during the period from October 2020 to April 2021. Results: We conducted ultrasound in 123 lymph nodes. To compare with the pathology results of the disease, there are 73 metastatic lymph nodes, 50 nonmetastatic lymph

${ }^{1}$ Học viện Quân y

²Bệnh viện Trung ương Quân đội 108

${ }^{3}$ Bệnh viện Quân y 103

Chịu trách nhiệm chính: Phan Hồng Quân

Email: phanhongquannd@gmail.com

Ngày nhận bài: 6.8.2021

Ngày phản biên khoa học: 1.10.2021

Ngày duyệt bài: 8.10.2021 nodes. Round shape, loss of an echogenic fatty hilum, echo, calcification, and abnormal vascularity were significantly more common in metastatic than nonmetastatic lymph nodes, whereas the boundary and size did not significantly differ. The sensitivity, specificity, positive predicted value, negative predicted value, the accuracy of 2D ultrasound method combined with Dopper ultrasound are 90,4\%, $84 \%$, $89,2 \%, 85,7 \%$ and $87,8 \%$. Conclusions: Within the limitations of this study, B-mode and CDUS evaluations were found to be highly significant with a high sensitivity and specificity. B-mode and CDUS examinations provide a prospect to reduce the need for biopsy/fine needle aspiration cytology in reactive nodes

Keywords: B-mode ultrasound, Doppler color ultrasonography, thyroid cancer, metastatic lymph node.

\section{I. ĐĂT VẤN ĐỀ}

Di căn hạch cổ là một loai di căn phổ biến của ung thư tuyến giáp. Có nhiều cách xác định tình trạng di căn hạch như khám lâm sàng, xét nghiệm nồng độ $\mathrm{Tg}$, siêu âm, chụp CLVT, xạ hình, PET/CT... Trong đó siêu âm là phương pháp đơn giản, kinh tế, dễ thực hiện ở các cơ sở y tế và rất an toàn cho bệnh nhân.

ở Việt Nam, còn ít thấy những công trình nghiên cứu một cách kỹ lưỡng về chẩn đoán đặc điểm hạch di căn trong UTTG thể biệt hóa sau phẫu thuật và điều trị ${ }^{131}$ I trên siêu âm. Vì vậy, chúng tôi tiến hành nghiên cứu mục tiêu "Xác định giá trị của siêu âm trong chẩn đoán hạch cổ di căn ở bênh nhân ung thư tuyến giáp thể biệt hóa sau phẫu thuật và điều trị ${ }^{131}$ I.".

\section{II. ĐỐI TƯỢNG VÀ PHƯƠNG PHÁP NGHIÊN CỨU}

1. Đối tượng: 61 bênh nhân được thực hiện siêu âm 2D, Dopper phát hiện 123 hạch cổ. Số hạch cổ trên được phân làm hai nhóm: nhóm I gồm 74 hạch cổ nghi ngờ hạch di căn trên siêu âm và nhóm II gồm 51 bệnh nhân siêu âm không nghi ngờ; có kết quả mô bệnh học khẳng định hạch ác tính hay lành tính.

2. Phương pháp nghiên cứu: mô tả hồi cứu kết hợp tiến cứu. Địa điểm thực hiện: Khoa chẩn đoán chức năng, bệnh viện Trung ương Quân đội 108 hiện:

3. Thiết bị sử dụng và phương pháp thực

- Sử dụng máy siêu âm LOGIQ S8, với đầu dò Linear tần số $7,5-15 \mathrm{~Hz}$. Bệnh nhân nằm ngửa, vùng cổ được bộc lộ hoàn toàn. Các cài đặt đã được chuẩn hóa và các bộ lọc tường, tân số lặp 
lại xung, độ tăng màu và độ sâu lấy nét được đặt ở chế độ tự động. Kỹ thuật được sử dụng là quét ngang liên tục và quét dọc bao phủ toàn bộ cổ ở cả hai bên nhằm đánh giá toàn bộ các nhóm hạch cổ I-VI. Việc thăm khám được bắt đầu bằng cắt ngang vùng dưới lưỡi, theo trình tự từ vùng dưới hàm đến vùng mang tai đến vùng trên, giữa và dưới cổ tử cung đến hố thượng đòn đên tam giác cổ sau. Ban đầu, thu thập các thông số về hạch trên siêu âm B-mode: đường kính trục ngắn, đường kính trục dài, vôi hóa, sự có hay không có mặt của rốn hạch, đường bờ và độ hồi âm. Sau đó, thực hiện siêu âm Doppler màu nhằm đánh giá đặc điểm tăng sinh mạch. Tất cả các bệnh nhân đều được thực hiện đầy đủ các bước trền và phẫu thuật vét hạch làm mô bệnh học

\section{KẾT QUẢ NGHIÊN CỨU}

1. Độ nhạy, độ đặc hiệu, giá trị tiên đoán dương, giá trị tiên đoán âm của đặc điểm hình dạng hạch trên siêu âm 2D

Bảng 1. Độ nhạy, độ đặc hiệu, giá trị tiên đoán dương, giá trị tiên đoán âm của đặc điểm hình dạng hạch trên siêu âm $2 D$

\begin{tabular}{|c|c|c|c|}
\hline $\begin{array}{l}\text { Mồ bệnh họd } \\
\text { Hình dang hach }\end{array}$ & $\begin{array}{c}\text { Ác } \\
\text { tính }\end{array}$ & $\begin{array}{l}\text { Lành } \\
\text { tính }\end{array}$ & Tổng \\
\hline Bầu dục (ngang/dọc <0.5) & 31 & 34 & 65 \\
\hline Tròn (ngang/dọc > $>0.5$ ) & 42 & 16 & 58 \\
\hline Tổng & 73 & 50 & 123 \\
\hline $\begin{array}{l}57,7 \\
\text { NPV }\end{array}$ & ; & $\begin{array}{l}=72 \\
8 \%\end{array}$ & \\
\hline
\end{tabular}

Nhận xét: Độ nhạy, độ đặc hiệu, giá trị tiên đoán đương, giá trị tiên đoán âm và độ chính xác tương ứng để dự đoán các hạch di căn của đặc điểm hình dạng hạch lần lượt là $57,7 \%$; $68 \%, 72,4 \% ; 52,3 \%$ và $61,8 \%$

2. Độ nhạy, độ đặc hiệu, giá trị tiên đoán dương, giá trị tiên đoán âm của đặc điểm mất rốn hạch trên siêu âm 2D

Bảng 2. Đố nhạ, độ đặc hiệu, giá trị tiên đoán dướng, giá trị tiển đoán âm của đặc điểm mất rốn hạch trên siêu âm $2 D$

\begin{tabular}{|c|c|c|c|}
\hline $\begin{array}{c}\text { Mô bệnh học } \\
\text { Rốn hạch }\end{array}$ & $\begin{array}{c}\text { Ác } \\
\text { tính }\end{array}$ & $\begin{array}{c}\text { Lành } \\
\text { tính }\end{array}$ & Tổng \\
\hline Còn & 11 & 34 & 45 \\
\hline Mất & 62 & 16 & 78 \\
\hline Tống & 73 & 50 & 123 \\
\hline \multicolumn{2}{|c|}{ Sn = 84,9\%; Sp = 68\%; PPV = 79,5\%; } \\
NPV = 75,6\%; Acc = 78\% \\
\hline
\end{tabular}

Nhận xét: Độ nhạy, độ đặc hiệu, giá trị tiên đoán dương, giá trị tiên đoán âm và độ chính xác tương ứng để dự đoán các hạch di căn của đặc điểm mất rốn hạch lần lượt là 84,9 \%; 68\%,
$79,5 \% ; 75,6 \%$ và $78 \%$

3. Độ nhạy, độ đặc hiệu, giá trị tiên đoán dương, giá trị tiên đoán âm của đặc điểm tăng âm hạch trên siêu âm 2D

Bảng 3. Độ nhạy, độ đặc hiệu, giá trị tiên đoán dương, giá trị tiên đoán âm của đặc điểm tăng âm hạch trên siêu âm $2 D$

\begin{tabular}{|c|c|c|c|}
\hline $\begin{array}{c}\text { Mố bệnh họ̣ hạch } \\
\text { Róc tính }\end{array}$ & $\begin{array}{c}\text { Lành } \\
\text { tính }\end{array}$ & Tổng \\
\hline Tăng âm & 30 & 7 & 37 \\
\hline Nang hóa/hoại tử & 7 & 1 & 8 \\
\hline Giảm âm & 29 & 42 & 71 \\
\hline Tăng âm+Nang hóa & 7 & 0 & 7 \\
\hline Tống & 73 & 50 & 123 \\
\hline
\end{tabular}

Sn $=41,1 \% ; \mathrm{Sp}=86 \% ; \mathrm{PPV}=81.1 \%$; $\mathrm{NPV}=50 \% ; \mathrm{AcC}=59,3 \%$

Nhận xét: Độ nhạy, độ đặc hiệu, giá trị tiên đoán dương, giá trị tiên đoán âm và độ chính xác tương ứng để dự đoán các hạch di căn của đặc điểm tăng âm hạch lần lượt là $41,1 \%$; 86\%, $81,1 \% ; 50 \%$ và $59,3 \%$

4. Độ nhạy, độ đặc hiệu, giá trị tiên đoán dương, giá trị tiên đoán âm của đặc điểm vôi hóa hạch trên siêu âm 2D

Bảng 4. Độ nhạ, độ đặc hiệu, giá trị tiên đoán dương, giá trị tiên đoán âm của đặc điểm vôi hóa hạch trên siêu âm 2D

\begin{tabular}{|c|c|c|c|}
\hline Mî bộ̂ hồnh học & $\begin{array}{c}\text { Ác } \\
\text { tính }\end{array}$ & $\begin{array}{c}\text { Lành } \\
\text { tính }\end{array}$ & Tổng \\
\hline Có & 27 & 3 & 30 \\
\hline Không & 46 & 47 & 93 \\
\hline Tống & 73 & 50 & 123 \\
\hline \multicolumn{2}{|c|}{} \\
\hline
\end{tabular}

Sn $=37 \% ; \mathrm{Sp}=94 \% ; \mathrm{PPV}=90 \%$;

$$
\mathrm{NPV}=50,5 \% ; A C C=60,2 \%
$$

Nhânn xét: Độ nhạy, độ đặc hiệu, giá trị tiên đoán dương, giá trị tiên đoán âm và độ chính xác tương ứng để dự đoán các hạch di căn của đặc điểm vi vôi hóa hạch lần lượt là $37 \%$; 94\%, $90 \% ; 50,5 \%$ và $60,2 \%$

5. Độ nhạy, độ đặc hiệu, giá trị tiên đoán dương, giá trị tiên đoán âm của đặc điểm tăng sinh mạch ngoại vi hạch trên siêu âm Doppler

Bảng 5. Độ nhạy, độ đặc hiệu, giá trị tiên đoán dương, giá trị tiên đoán âm của đặc điểm tăng sinh mạch ngoại vi hạch trên siêu âm Doppler

\begin{tabular}{|c|c|c|c|}
\hline $\begin{array}{c}\text { Mố bệnh học } \\
\text { Mạch máu hạch }\end{array}$ & $\begin{array}{c}\text { Ác } \\
\text { tính }\end{array}$ & $\begin{array}{c}\text { Lành } \\
\text { tính }\end{array}$ & Tổng \\
\hline Ngoại vì & 36 & 4 & 40 \\
\hline Trung tâm & 7 & 2 & 9 \\
\hline Hốn hợp & 10 & 3 & 13 \\
\hline Không TSM & 20 & 41 & 61 \\
\hline Tổng & 73 & 50 & 123 \\
\hline
\end{tabular}


Sn $=49,3 \% ; \mathrm{Sp}=92 \% ; \mathrm{PPV}=90 \%$; $\mathrm{NPV}=55,4 \% ;$ Acc $=66,7 \%$

Nhận xét: Độ nhạy, độ đặc hiệu, giá trị tiên đoán dương, giá trị tiên đoán âm và độ chính xác tương ứng để dự đoán các hạch di căn của đặc điểm tăng sinh mạch ngoại vì hạch lần lượt là $49,3 \% ; 92 \%, 90 \% ; 55,4 \%$ và $66,7 \%$

6. Giá trị siêu âm trong chẩn đoán hạch cổ di căn

Bảng 6 Giá trị siêu âm trong chẩn đoán hạch cố di căn

\begin{tabular}{|c|c|c|c|}
\hline Siêu âm Mô bệnh học & $\begin{array}{c}\text { Lành } \\
\text { tính (n) }\end{array}$ & $\begin{array}{l}\text { Ác tinh } \\
\text { (n) }\end{array}$ & Tổ \\
\hline Nghi ngờ di căn & 66 & 8 & 74 \\
\hline Không nghi ngờ di căn & 7 & 42 & 49 \\
\hline Tống & 73 & 50 & 123 \\
\hline
\end{tabular}

Nhận xét: Đối chiếu kết quả giải phẫu bệnh, độ nhạy, độ đặc hiệu, giá trị chẩn đoán dương tính, giá trị chẩn đoán âm tính, độ chính xác của phương pháp siêu âm 2D kết hợp siêu âm Dopper lần lượt là $\mathrm{Sn}=90,4 \% ; \mathrm{Sp}=84 \%$; PPV $=89,2 \% ; \mathrm{NPV}=85,7 \% ; \mathrm{Acc}=87,8 \%$

$$
\text { ROC Curve }
$$

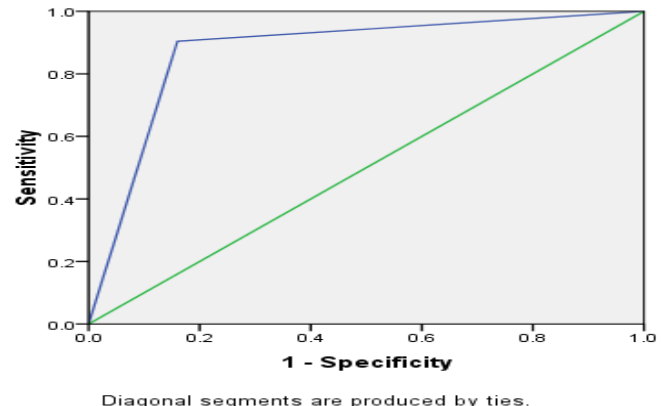

Hình 1 : Đường cong ROC thể hiện môî liên
hệ giữa các đặc điểm trên siêu ầm với các
hạch bach huyết di căn

Đường cong ROC thể hiện mối liên hệ giữa các đặc điểm trên siêu âm với các hạch bạch huyết di căn (Hình 1). Diện tích dưới đường cong là 0,872 , cho thây độ chính xác của phép thử là tốt.

\section{BÀN LUẬN}

Trong nghiên cứu của chúng tôi tiến hành trên 61 bệnh nhân với 123 hạch; dựa vào kết quả mô bệnh học, xác định được trong tổng số 123 hạch có 73 hạch di cằn và 50 hạch lành tính. Chúng tôi nhận thấy có sự khác biệt giữa các hạch di căn và các hạch không di cắn trên siêu âm 2D và Doppler ở các đặc điểm như: Hình dạng hạch, mất rốn hạch, hồi âm hạch, vi vôi hóa, tăng sinh mạch.
Nếu chỉ dựa vào một trong số những đặc điểm trên của hạch trên siêu âm để chẩn đoán hạch di căn, chúng tôi ghi nhận kết quả như sau:

- Độ nhạy, độ đặc hiệu, giá trị tiên đoán dương, giá trị tiền đoán âm và độ chính xác tương ứng để dự đoán các hạch di căn của đặc điểm hình dạng hạch lần lượt là $57,7 \%$; $68 \%$, $72,4 \% ; 52,3 \%$ và $61,8 \%$ (Bảng 1 ). Hạch ác tính có xu hướng tròn hơn hạch lành tính, tuy nhiên nó không được coi tiêu chí riêng biệt để đánh giá giữa lành và ác tính do hạch dưới cằm, dưới hàm bình thường có xu hướng tròn [3].

Theo Zeming Liu và $\mathrm{CS}$, Độ nhạy, độ đặc hiệu, giá trị tiên đoán dương, giá trị tiên đoán âm và độ chính xác tương ứng để dự đoán các hạch di căn của đặc điểm hình tròn là $41,4 \%$; $75,9 \% ; 49,1 \% ; 69,8 \%$ và $63,5 \%$ [2]

- Độ nhạy, độ đặc hiệu, giá trị tiên đoán dương, giá trị tiển đoán âm và độ chính xác tương ứng đế dự đoán các hạch di căn của đặc điểm mất rốn hạch lần lượt là $84,9 \% ; 68 \%$, $79,5 \% ; 75,6 \%$ và $78 \%$ ( Bảng 2).

Theo Zeming Liu và CS, Độ nhạy, độ đặc hiệu, giá trị tiên đoán dương, giá trị tiên đoán âm và độ chính xác tương ứng để dự đoán các hạch di căn của đặc điểm mất rốn hạch là 9,7\%; $98,7 \% ; 92,7 \% ; 71,4 \%$ và $73,9 \%$

- Độ nhạy, độ đặc hiệu, giá trị tiên đoán dương, giá trị tiên đoán âm và độ chính xác tương ứng để dự đoán các hạch di căn của đặc điểm hồi âm hạch lần lượt là $41,1 \% ; 86 \%$, $81,1 \% ; 50 \%$ và $59,3 \%$ (Bảng 3 ). Có sự khác biệt đáng kể về tính chất âm của hai nhóm. Hạch di căn có tỷ lệ tăng âm cao hơn so với hạch không di căn, điều này giải thích do thành phẩn hạch di căn có chứa thyroglobulin [4].

- Độ nhạy, độ đặc hiệu, giá trị tiên đoán dương, giá trị tiển đoán âm và độ chính xác tương ứng đế dự đoán các hạch di căn của đặc điểm vi vôi hóa hạch lần lượt là 37\%; 94\%, $90 \% ; 50,5 \%$ và $60,2 \%$ (Bảng 4 ).

Theo Zeming Liu và CS, Độ nhạy, độ đặc hiệu, giá trị tiên đoán dương, giá trị tiên đoán âm và độ chính xác tương ứng để dự đoán các hạch di căn của đặc điểm vi vôi hóa là $34,4 \%$; $94,3 \% ; 77,2 \% ; 71,9 \% ; 72,8 \%$ [2]

- Độ nhạy, độ đặc hiệu, giá trị tiên đoán dương, giá trị tiên đoán âm và độ chính xác tương ứng để dự đoán các hạch di căn của đặc điểm tăng sinh mạch ngoại vi hạch lần lượt là $49,3 \% ; 92 \%, 90 \% ; 55,4 \%$ và $66,7 \%$ (Bảng 5 ). Sự tăng sinh mạch ngoại vi hạch giải thích một phần do dự sự phá hủy hệ mạch máu của các tế bào u trong các hạch ác tính có thể là do chất 
cảm ứng tăng sinh mạch do tế bào u kích thích tạo ra [5]

Theo Zeming Liu và CS, Độ nhạy, độ đặc hiệu, giá trị tiên đoán dương, giá trị tiên đoán âm và độ chính xác tương ứng để dự đoán các hạch di căn đặc điểm mạch máu bất thường là $32,8 \% ; 77,6 \% ; 45,2 \% ; 67,3 \% ; 61,5 \%$

Kết hợp từ 2 đặc điểm siêu âm trở lên để chẩn đoán hạch cổ di căn ở bệnh nhân UTTGTBH đã phẫu thuật cắt giáp và điều trị 131I, siêu âm phát hiện được 74 hạch di căn và 49 hạch không di căn trong tổng số 123 hạch (Bảng 6). Đối chiếu với kết quả mô bệnh học, chúng tôi thấy độ nhạy (Sn), độ đặc hiệu (Sp), giá trị chẩn đoán dương tính (PPV), giá trị chẩn đoán âm tính (NPV), độ chính xác (Acc) của phương pháp siêu âm 2D kết hợp siêu âm Dopper lần lượt là $90.4 \%, 84 \%, 89.2 \%, 85.7 \%$ và $87.8 \%$.

Theo Nguyễn Thanh Thủy và CS, độ nhạy (Sn), độ đặc hiệu (Sp), giá trị chẩn đoán dương tính (PPV), giá trị chẩn đoán âm tính (NPV), độ chính xác (ACc) của phương pháp siêu âm 2D kết hợp siêu âm Dopper lần lượt là 95,08\%, 79,2\%, $92 \%, 86 \%$ và $90,6 \%$. [1]

Đường cong ROC thể hiện mối liên hệ giữa các đặc điểm trên siêu âm với các hạch bạch huyết di căn (Hình 1). Diện tích dưới đường cong là 0,872 , cho thây độ chính xác của phép thử là tốt.

Trong nghiên cứu của Zeming Liu và CS, Đường cong ROC thể hiện mối liên hệ giữa các đặc điểm trên siêu âm với các hạch bạch huyết di căn có diện tích dưới đường cong là 0,793.

\section{KẾT LUẦN}

Nghiên cứu của chúng tôi cho thây rằng các đặc điểm trên siêu âm về hình dạng tròn, hồi âm, vôi hóa, mất rốn hạch và tăng sinh mạch bất thường là những tiêu chuẩn siêu âm hữu ích để phân biệt giữa các hạch cổ di căn và không có di căn trên bệnh nhân ung thư tuyến giáp thể biệt hóa đã phẫu thuật và điều trị ${ }^{131} \mathrm{I}$. Độ nhạy, độ đặc hiệu, giá trị tiên đoán dương, giá trị tiên đoán âm, độ chính xác của phương pháp siêu âm 2D kết hợp với Dopper lần lượt là 90,4\%, $84 \%, 89,2 \%, 85,7 \%$ và $87,8 \%$.

\section{TÀI LIÊU THAM KHẢO}

1. Nguyễn Thanh Thủy (2020), "' Nghiên cứu đặc điểm hình ảnh hạch ác tính trên siêu âm và giá trị của siêu âm trong chẩn đoán hạch ác tính tại bệnh viên Bạch Mai", Tạp chi Điện Quang Việt Nam. 39, tr. $\operatorname{tr} 68-75$.

2. Liu, Z., et al.(2017), Diagnostic accuracy of ultrasonographic features for lymph node metastasis in papillary thyroid microcarcinoma: a single-center retrospective study. World J Surg Oncol, 15(1): p. 32

3. Ying, M., et al., Sonographic appearance and distribution of normal cervical lymph nodes in a Chinese population. J Ultrasound Med, 1996. 15(6): p. 431-6.

4. Ahuja, A.T., et al., Metastatic cervical nodes in papillary carcinoma of the thyroid: ultrasound and histological correlation. Clin Radiol, 1995. 50(4): p. 229-31.

5. Ying, M., et al., Power Doppler sonography of normal cervical lymph nodes. J Ultrasound Med, 2000. 19(8): p. 511-7

\section{ĐĂC ĐIỂM LÂM SÀNG CỦA BỆNH NHÂN TRÀO NGƯỢC DẠ DÀY THỰC QUẢN}

\section{TÓM TẮT.}

Mục tiêu: Mô tả đặc điểm lâm sàng của bệnh nhân trào ngược da dày thực quản tại Bệnh viện đa khoa Y học cổ truyển Hà Nội. Đối tượng: Bệnh nhân trào ngược dạ dày thực quản đến khám và điêu trị từ tháng 06/2021 đến tháng 09/2021. Phương pháp: Nghiên cứu mô tả cắt ngang. Kết quả: Trong thời

*Bệnh viện Đa khoa tỉnh Lào Cai

**Bệnh viện đa khoa YHCT Hà Nội

***Trường Đại học Y Hà Nội

Chịu trách nhiệm chính: Nguyễn Thị Thanh Tú

Email: thanhtu@hmu.edu.vn

Ngày nhận bài: 4.8.2021

Ngày phản biện khoa học: 1.10.2021

Ngày duyệt bài: 7.10.2021

\section{Lý Hải Yến*, Vũ Minh Hoàn**, Nguyễn Thị Thanh Tú ***}

gian nghiên cứu, bệnh viện Y hơc cổ truyền Hà Nội đã điều trị cho 60 bệnh nhẩn: Tuổi trung bình của beẹnh nhân nghiên cứu là $51,95 \pm 15,94$. Tỉ lệ nữ cao hớn nam $(66,67 \%)$. Phần lớn bệnh nhân là lao động trí óc $(38,33 \%)$. Thời gian bị bệnh chủ yếu từ 6 đến 12 tháng $(61,67 \%)$. Có 30,0\% bệnh nhân có sử dụng bia rượu, 21,67\% hút thuốc lá, 33,33\% thường xuyên uống cà phê, $55 \%$ sử dụng thuốc giảm đau nonsteroid; $38,33 \%$ bệnh nhân thứa cân và béo phì. Triệu chứng ợ chua, ợ hơi chiếm tî lệ cao nhất $(88,33 \%)$. Tồng điểm GERD $Q$ trung bình của bệnh nhân khi vào viên là $10,42 \pm 1,72$. Kêt luận: Nghiên cứu đã mô tả đặc điểm lâm sàng của bệnh nhân trào ngược dạ dày thực quản và một số yêu tố liên quan đến bênhi trào ngược dạ dày thực quản.

Từ khóa: Trào ngược dạ dây thực quản, đặc điểm lâm sàng 